\title{
Methicillin-resistant Staphylococcus aureus nasal colonization among HIV-infected patients in Taiwan: prevalence, molecular characteristics and associated factors with nasal carriage
}

Yi-Yu Hsu', David Wu², Chien-Ching Hung ${ }^{3}$, Shie-Shian Huang ${ }^{4,5}$, Fang-Hsueh Yuan ${ }^{6}$, Ming-Hsun Lee ${ }^{4,6}$, Ching-Tai Huang ${ }^{4,6}$, Shian-Sen Shie ${ }^{4,6}$, Po-Yen Huang ${ }^{4,6}$, Chien-Chang Yang ${ }^{4,6}$, Chun-Wen Cheng ${ }^{4,6}$, Hsieh-Shong Leu ${ }^{4,6}$, Ting-Shu Wu ${ }^{4,6}$ and Yhu-Chering Huang ${ }^{4,7,8 *}$

\begin{abstract}
Background: To evaluate nasal carriage, antibiotic susceptibility and molecular characteristics of methicillin-resistant Staphylococcus aureus (MRSA), as well as the risk factors of MRSA colonization, in human immunodeficiency virus (HIV)-infected patients in northern Taiwan.

Methods: From September 2014 to November 2015, HIV-infected patients seeking outpatient care at four hospitals were eligible for this study. A nasal specimen was obtained from each subject for the detection of $S$. aureus and a questionnaire was completed by each subject. MRSA isolates once identified were characterized.

Results: Of 553 patients surveyed, methicillin-susceptible S. aureus (MSSA) was detected in 119 subjects (21.5\%) and MRSA in 19 subjects (3.4\%). Female gender, injection drug use, smoking, hepatitis C virus carrier, cancer and antibiotic use within 1 year were positively associated with MRSA colonization. By multivariate analysis, only cancer (adjust odds ratio (aOR) 7.78, [95\% confidence interval (Cl), 1.909-31.731]) and antibiotic use within 1 year (aOR 3.89, [95\% Cl, 1.219-12.433]) were significantly associated with MRSA colonization. Ten isolates were characterized as sequence type (ST) 59/staphylococcal chromosome cassette (SCC) IV or $V_{T}$, endemic community strains in Taiwan, four isolates as ST 8/SCCmec IV (USA 300) and one isolate as ST 239/SCCmec IIIA, a hospital strain. All the community-associated MRSA isolates were susceptible to trimethoprim-sulfamethoxazole (TMP-SMX).

(Continued on next page)
\end{abstract}

\footnotetext{
* Correspondence: ychuang@cgmh.org.tw

${ }^{4}$ Department of Medicine, Chang Gung University School of Medicine, Kweishan, Taoyuan, Taiwan

${ }^{7}$ Division of Pediatric Infectious Diseases, Chang Gung Memorial Hospital at Linkou, Kweishan, Taoyuan, Taiwan

Full list of author information is available at the end of the article
}

(c) The Author(s). 2020 Open Access This article is licensed under a Creative Commons Attribution 4.0 International License, which permits use, sharing, adaptation, distribution and reproduction in any medium or format, as long as you give appropriate credit to the original author(s) and the source, provide a link to the Creative Commons licence, and indicate if changes were made. The images or other third party material in this article are included in the article's Creative Commons licence, unless indicated otherwise in a credit line to the material. If material is not included in the article's Creative Commons licence and your intended use is not permitted by statutory regulation or exceeds the permitted use, you will need to obtain permission directly from the copyright holder. To view a copy of this licence, visit http://creativecommons.org/licenses/by/4.0/. The Creative Commons Public Domain Dedication waiver (http://creativecommons.org/publicdomain/zero/1.0/) applies to the data made available in this article, unless otherwise stated in a credit line to the data. 


\begin{abstract}
(Continued from previous page)
Conclusions: Nasal MRSA carriage in HIV-infected patients seeking outpatient care was low (3.4\%) in northern

Taiwan. Most of the colonizing isolates were genetically endemic community strains and exhibited high

susceptibility to TMP-SMX and fluoroquinolones. Cancer and antibiotic use within 1 year were associated with MRSA colonization.
\end{abstract}

Keywords: Nasal carriage, Antibiotic use, Injection drug use, Injection drug user, Molecular typing

\section{Background}

Methicillin-resistant Staphylococcus aureus (MRSA) was first reported in the 1960s [1] and the infections due to MRSA rapidly increased in the 1980s [2-4], most of which were health care-acquired infections. In the late 1990s, MRSA began to be recognized as a major cause of community-onset infections, which was termed as community-associated MRSA (CA-MRSA) later [2-4]. The epidemic of CA-MRSA has spread rapidly both in the community [2-4] and in healthcare settings over the past decade. Carriage of $S$. aureus, including MRSA, has been identified as a predisposing factor for subsequent invasive infections $[5,6]$, and the anterior nares are the most common site of colonization.

Among human immunodeficiency virus (HIV)-infected patients, $S$. aureus infection is considered to be a major cause of significant morbidity and mortality [7-9]. Previous studies suggest that prevalence of nasal colonization with MRSA is higher in HIV-infected individuals than in the general population [10-12]. HIV infection is also related to persistent colonization [13]. The higher colonization burden may be associated with a higher incidence of subsequent infections [10,11, 14]. However, risk factors for $S$. aureus colonization appear to be different among different populations, including patients infected with HIV [11, 15-17]. MRSA colonization in HIV-infected patients may vary widely in different geographical regions $[15,18-21]$, the time point of survey [14], and the coverage of antiretroviral therapy in the population [22].

MRSA has been a prevalent etiology of infections in Asian countries, including Taiwan, either in healthcare settings or in the community, for decades, but the reports regarding MRSA colonization in HIV-infected population have been scarce $[12,15,23]$. Hence, we conducted this study to evaluate the prevalence of and associated factors for MRSA colonization in HIV-infected population in Taiwan. All collected MRSA isolates were further characterized by molecular methods and antibiotic susceptibility.

\section{Methods}

The study was approved by the institutional review board (IRB) of Chang Gung Memorial Hospital (protocol number:103-2418A3) and the Research Ethics Committee of National Taiwan University Hospital. A written informed consent was obtained from each subject.

\section{Subject enrollment}

The study was conducted in hospital-based infectious diseases outpatient clinics at Chang Gung Memorial Hospital (CGMH) and National Taiwan University Hospital (NTUH) from September 2014 to November 2015. Both CGMH and NTUH are university-affiliated medical centers situated in northern Taiwan. Data were obtained in multiple CGMH branches, including Linkou branch, Taipei branch and Keelung branch. We also recruited patients from prison and correctional facilities in Keelung, where inmates were regularly followed by infectious diseases specialists in CGMH Keelung branch. All the HIV-infected patients who visited and treated at CGMH and NTUH were eligible and invited to participate in this study. Study subjects were enrolled when they sought HIV care at the infectious diseases outpatient departments.

\section{Data collection}

To identify the associated factors with MRSA acquisition, a self-administered questionnaire interview was performed to inquire into the factors for colonization with MRSA in HIV-infected patients. The following information was also collected from medical records of the participants: age, gender, drinking habits and smoking habits, underlying diseases, clinical characteristics, latest hospitalization, community exposure (eg, drug use, and incarceration), previous $S$. aureus infection, antibiotic use, skin disease, plasma HIV RNA load and $\mathrm{CD} 4+\mathrm{T}$ lymphocytes, and antiretroviral therapy. Clinical information regarding hospitalization, residence in a long-term care facility, outpatient department visit, surgery, dialysis, and usage of tubes (nasogastric tube, urine catheter, tracheostomy tube, drainage tube, port-A, and dialysis tube) were also obtained. Substance abuse was defined as current or former use if illicit drugs.

\section{Microbiologic study}

Nasal specimens were obtained by swabbing the anterior $1 \mathrm{~cm}$ of the nasal vestibule of both anterior nares of the participants. The swabs were preserved in the transport medium (Venturi Transystem, Copan Innovation Ltd.) 
immediately. S. aureus was identified by colony morphology, Gram stain, positive coagulase tests, and presence of $\beta$-hemolysis after subculture to tryptic soy agar plates containing 5\% sheep's blood. Methicillin resistance was confirmed by cefoxitin disk-diffusion method according to the recommendation of Clinical and Laboratory Standard Institutes [24].

\section{Antimicrobial susceptibility study}

The antimicrobial susceptibility of all MRSA isolates to ten antibiotics, including ciprofloxacin, trimethoprim/ sulfamethoxazole (SXT), penicillin, teicoplanin, linezolid, clindamycin, doxycyclin, fusidic acid, vancomycin, and erythromycin, was tested in accordance with the guideline of Clinical and Laboratory Standard Institutes by using the disk-diffusion method [24].

\section{Molecular characterization}

All the MRSA isolates, once identified, were characterized by molecular methods. By pulsed-field gel electrophoresis (PFGE) with SmaI digestion [25-27], the genotypes were designated in alphabetical order, as in our previous studies [25-27]; any new genotype, if identified, was designated consecutively. PFGE patterns with fewer than four band differences from an existing genotype were defined as subtypes of that genotype. Staphylococcal chromosome cassette mec (SCCmec) type, and the presence of Panton-Valentine leukocidin (PVL) genes were determined by a multiplex PCR strategy [28]. Some isolates of representative PFGE patterns were selected and underwent multilocus sequence typing (MLST) [29] and spa typing [27]. The allelic profiles were assigned through comparison of the sequences at each locus with those of the known alleles in the $S$. aureus MLST database and were defined as sequence types accordingly. The details of the procedures were described elsewhere previously [25-29].

\section{Statistical analysis}

Statistical analyses were performed with the Statistical Package for the Social Sciences (SPSS software for Windows, version 17.0). The definition of statistical significance was $p<0.05$. Chi-square analysis or Fisher's exact test was used for examination of categorical variables. Continuous variables were compared between patients with MRSA colonization versus patients without MRSA colonization using two-sample t-test, in which Levene's test was used to determine equality of variances between the two groups.

\section{Results}

During the 14-month study period, a total of 810 HIVinfected patients sought outpatient care at CGMH and NTUH (446 from CGMH and 364 from NTUH). Of the
810 eligible patients, 586 patients (275 from CGMH and 311 from NTUH) were interviewed and invited to participate in this study. Five hundred fifty-three patients (259 from CGMH and 294 from NTUH) were enrolled in total and were surveyed for nasal carriage of MRSA after giving their written informed consent.

Detailed demographic data are shown in Table 1. Five hundred thirty-one were male (96\%) and 22 female (4\%). The majority of the participants were aged 20-60 years (with $47.6 \%$ between 20 and 39 years, and $45.6 \%$ between 40 and 60 years). The main route of HIV acquisition was male-to-male sex contact (68.0\%), followed by injection drug use (16.3\%). Table 1 shows the comparison among different hospitals and no statistically significant difference was found among different hospitals in terms of nasal MRSA carriage rate among the HIV-infected patients.

The overall MSSA and MRSA nasal colonization rate was 21.5 and $3.4 \%$, respectively. The comparison of underlying diseases and other medical history between patients with and without MRSA colonization are shown in Tables 2 and 3. In univariate analysis, we found that female gender $(p=0.005)$, injection drug use $(p=0.001)$, smoking $(p=0.02)$, hepatitis $\mathrm{C}$ virus $(\mathrm{HCV})$ carrier $(p=$ $0.003)$, cancer $(\mathrm{p}=0.001)$ and antibiotic use within 1 year $(p=0.02)$ were significant factors associated with MRSA colonization. CD4 + T lymphocytes or plasma HIV RNA load was not significantly associated with MRSA colonization. By multivariate analysis, cancer (adjust odds ratio (aOR) 7.78, [95\% confidence interval (CI), 1.909-31.731]) and antibiotic use within 1 year (aOR 3.89 , [95\% CI, 1.219-12.433]) were significantly associated with MRSA colonization.

All 19 MRSA isolates were available for molecular characterization and the distribution of PFGE patterns, SCCmec types, SPA typing, and the presence of PVL genes among the 19 MRSA isolates are shown in Fig. 1. MLST was selectively done in 11 isolates, and five sequence types were identified. Totally six PFGE patterns were identified. One isolate carried SCCmec type IIIA and the remaining isolates carried either SCCmec type IV or VT. PFGE pattern D/ sequence type (ST) 59 was the relatively common clone, followed by PFGE pattern C/ST 59 and PFGE pattern AI/ST 8. PVL is one of the most important virulence factors of $S$. aureus and PVL genes were present in 9 isolates (47\%). PVL genes were present in all isolates with PFGE pattern AI/ST 8 and most isolates with PFGE pattern D/ST 59/SCCmec $\mathrm{V}_{\mathrm{T}}$, but absent in isolates with PFGE pattern AG4/ST 30 and C/ST 59/SCCmec IV.

All the MRSA strains were resistant to penicillin and susceptible to linezolid, teicoplanin, doxycycline, and vancomycin. The susceptibility rates to erythromycin, clindamycin, ciprofloxacin, trimethoprim-sulfamethoxazole 
Table 1 Comparison of demographics and transmission vehicles between HIV-infected patients with and without methicillinresistant Staphylococcus aureus (MRSA) nasal colonization

\begin{tabular}{|c|c|c|c|c|}
\hline \multirow[t]{2}{*}{ Characteristic } & \multicolumn{3}{|c|}{ No. (\%) of subjects } & \multirow{2}{*}{$\begin{array}{l}P \\
\text { value }\end{array}$} \\
\hline & Total $(n=553)$ & MRSA carriers $(n=19)$ & Non-MRSA carriers $(n=534)$ & \\
\hline Age in years, mean (SD) & $41.2(11.4)$ & $43.8(13.0)$ & $41.1(11.3)$ & 0.296 \\
\hline \multicolumn{5}{|l|}{ Gender } \\
\hline Male & $531(96)$ & $15(79)$ & $516(97)$ & \multirow[t]{2}{*}{0.005} \\
\hline Female & $22(4)$ & $4(21)$ & $18(3)$ & \\
\hline \multicolumn{5}{|l|}{ Route of HIV transmission } \\
\hline Injection drug use & $90(16)$ & $9(47)$ & $81(15)$ & 0.001 \\
\hline Heterosexual activity & $62(11)$ & $2(11)$ & $61(11)$ & 1.000 \\
\hline Male-to-male sex & $375(68)$ & $6(32)$ & $369(69)$ & 0.002 \\
\hline Blood transfusion & $3(0.5)$ & $0(0)$ & $3(0.6)$ & 1.000 \\
\hline Vertical transmission & $1(0.2)$ & $0(0)$ & $1(0.2)$ & 1.000 \\
\hline Unknown & $36(6.5)$ & $2(11)$ & $34(6.4)$ & 0.380 \\
\hline Facility & & & & 0.203 \\
\hline CGMH, Linko branch & $111(20.1)$ & $3(15.8)$ & $108(20.2)$ & \\
\hline CGMH, Taipei branch & $13(2.4)$ & $0(0)$ & $13(2.4)$ & \\
\hline CGMH, Keelung branch & $117(21.2)$ & $8(42.1)$ & $109(20.4)$ & \\
\hline Keelung jail and prison & $18(3.3)$ & $1(5.3)$ & $17(3.2)$ & \\
\hline NTUH & $294(53.2)$ & $7(36.8)$ & $287(53.8)$ & \\
\hline
\end{tabular}

Abbreviations: CGMH Chang Gung Memorial Hospital, NTUH National Taiwan University Hospital

*significant difference $(p<0.05)$

(TMP-SMX), and fusidic acid were 15.8, 42.1, 84.20, 94.7, and $89.5 \%$, respectively.

\section{Discussion}

To our knowledge, this is the largest study on this issue in Asian countries [15]. In this cross-section survey among $553 \mathrm{HIV}$-infected patients seeking care at the outpatient clinics in four hospitals in northern Taiwan, we found that the overall prevalence of MRSA nasal carriage among the $\mathrm{HIV}$-infected individual was $3.4 \%$ while the prevalence of MSSA nasal carriage was $21.5 \%$. The nasal carriage of MRSA was associated with cancer and antibiotic exposure within the past 12 months.

The nasal carriage rate of MRSA in this study is slightly lower than that previously reported in Taiwan in 2003 (5.6\% of 296 HIV-infected patients) [12] and in 2009-2010 (4.4\% of 457 HIV-infected patients) [23]. Compared with other populations in Taiwan, the nasal MRSA carriage rate among HIV-infected patients was significantly lower than that for patients hospitalized in the intensive care units (ICU) (32\% of 177 patients) [30], but similar to that for adult patients receiving hemodialysis (3.8\% of 296 patients) [31], adult patients visiting emergency room (3.8\% of 502 patients) [32] and otherwise healthy adults for health examination (3.8\% of 3098 adults) [33]. It could be explained that in the era of highly active antiretroviral therapy (HAART), the majority of the HIV-infected patients recruited in this study came from community settings, outpatient visiting and these patients were not frequently exposed to the highrisk populations for MRSA acquisition, such as patients admitted to the ICUs.

For patients infected with HIV, the nasal MRSA carriage rate was different, with a huge discrepancy, in different countries and regions. A latest meta-analysis on this issue [15] showed that the estimated pooled worldwide prevalence of MRSA in HIV-infected people is around 7\% (5$9 \%)$, with the prevalence of $7-13 \%$ in the region of the Americas and $0-1 \%$ in the European region. Compared with other Asian countries, the prevalence rate (3.4\%) in this study was lower than that in India (6-26\%), as well as in Singapore (3-10\%) but higher than that in Malaysia (< $1 \%)$. This variation may be attributable to different prevailing MRSA clones, study population, the intermittent nature of colonization [10] and different culture of antibiotic use between countries [34].

We observed that MRSA colonization was associated with antibiotic use within 12 months among HIVinfected individuals. This finding supported previous observations that recent receipt of antibiotics was strongly associated with MRSA colonization [12]. Wang et al. found that smoking was a protective factor against MRSA colonization in the community setting [33], which was not confirmed in this study. The potential reasons for the disparity might be the difference in 
Table 2 Analysis of risk factors for nasal colonization with methicillin-resistant Staphylococcus aureus (MRSA) among HIV-infected outpatients

\begin{tabular}{|c|c|c|c|c|}
\hline \multirow[t]{2}{*}{ Characteristic } & \multicolumn{3}{|c|}{ No. (\%) of subjects } & \multirow{2}{*}{$\begin{array}{l}P \\
\text { value }\end{array}$} \\
\hline & Total $(n=553)$ & MRSA carriers $(n=19)$ & Non-MRSA carriers $(n=534)$ & \\
\hline \multicolumn{5}{|l|}{ Personal history } \\
\hline Smoking & $290(52)$ & $15(79)$ & $275(51)$ & $0.020^{*}$ \\
\hline Alcohol Drinking & $139(25)$ & $6(32)$ & $133(25)$ & 0.590 \\
\hline Hospitalization after HIV diagnosis & $269(49)$ & $7(37)$ & $262(49)$ & 0.354 \\
\hline Recent hospitalization within 1 year & $80(14)$ & $5(26)$ & $75(14)$ & 0.174 \\
\hline Operation history & $16(3)$ & $0(0)$ & $16(3)$ & 1.000 \\
\hline Nurse home & $3(0.6)$ & $0(0)$ & $3(0.6)$ & 1.000 \\
\hline \multicolumn{5}{|l|}{ Underlying diseases } \\
\hline Hypertension & $59(11)$ & $3(16)$ & $56(10)$ & 0.443 \\
\hline DM & $21(4)$ & $1(5)$ & $20(4)$ & 0.527 \\
\hline Arrhythmia history & $10(2)$ & $1(5)$ & $9(2)$ & 0.297 \\
\hline Angina history & $7(1)$ & $0(0)$ & $7(1)$ & 1.000 \\
\hline Pneumonia history & $26(5)$ & $1(5)$ & $25(5)$ & 0.606 \\
\hline COPD & $6(1)$ & $0(0)$ & $6(1)$ & 1.000 \\
\hline Asthma & $12(2)$ & $0(0)$ & $12(2)$ & 1.000 \\
\hline Tuberculosis & $20(4)$ & $1(5)$ & $19(4)$ & 0.509 \\
\hline HBV carrier & $62(11)$ & $2(11)$ & $60(11)$ & 1.000 \\
\hline HCV carrier & $123(22)$ & $10(53)$ & $113(21)$ & $0.003^{*}$ \\
\hline Cirrhosis & $3(0.5)$ & $1(5)$ & $2(0.4)$ & 0.100 \\
\hline CKD & $10(2)$ & $1(5)$ & $9(2)$ & 0.297 \\
\hline Cancer & $27(5)$ & $5(26)$ & $22(4)$ & $0.001^{*}$ \\
\hline \multicolumn{5}{|l|}{ Recent infectious diseases (within 3 months) } \\
\hline Recent URI & $62(11)$ & $2(11)$ & $60(11)$ & 1.000 \\
\hline Skin infection & $29(5)$ & $1(5)$ & $28(5)$ & 1.000 \\
\hline Unhealed wound & $16(3)$ & $1(5)$ & $15(3)$ & 0.433 \\
\hline UTI & $6(1)$ & $0(0)$ & $6(1)$ & 1.000 \\
\hline \multicolumn{5}{|l|}{ Recent treatment (in 3 months) } \\
\hline On all catheters & $10(2)$ & $1(5)$ & $9(2)$ & 0.297 \\
\hline Hemodialysis & $2(0.3)$ & $1(5)$ & $1(0.2)$ & 0.068 \\
\hline Antibiotic use in 1 year & $88(16)$ & $7(37)$ & $81(15)$ & $0.020^{*}$ \\
\hline \multicolumn{5}{|l|}{ Laboratory data } \\
\hline CD4 count (cells/uL), mean \pm SD & & $469.16 \pm 214.8$ & $540.61+292.3$ & 0.292 \\
\hline Plasma HIV RNA load ( $\log _{10}$ of copies/ml), mean \pm SD & & $1.341 \pm 2.055$ & $0.929 \pm 1.660$ & 0.293 \\
\hline
\end{tabular}

Abbreviations: DM diabetes mellitus, COPD chronic obstructive pulmonary disease, $H B V$ hepatitis B virus, $H C V$ hepatitis $C$ virus, CKD chronic kidney disease, URI upper respiratory infection, $S D$ standard deviation

*significant difference $(p<0.05)$

questionnaire design. A latest meta-analysis on this issue [15] indicated that the risk factors for MRSA colonization included having a previous MRSA infection, hospitalization in the past year and use of antibiotics in the past 6 months.

Molecular characterization of MRSA isolates in the present study showed that $10(52.6 \%)$ of the 19 isolates belonged to ST59 linage, the predominant communityassociated MRSA strain in Taiwan. One isolate was characterized by ST239-SCCmec IIIA which had been known as the most dominant healthcare-associated MRSA clone in Taiwan [4]. The patient with the isolate of ST239 did have a medical history of recent hospitalization within the past year and had been admitted four times after being diagnosed with HIV. The remaining eight isolates carried type IV SCCmec. Among these eight isolates, four of them were identified and confirmed as USA 300 later [35], the 
Table 3 Multivariate analysis of factors associated with nasal colonization of MRSA in HIV carriers in Taiwan

\begin{tabular}{llll}
\hline Factor & Adjust odds ratio & $95 \%$ confidence interval & $P$ value \\
\hline Female Gender & 2.910 & $0.690-12.276$ & 0.1459 \\
Injection drug user & 1.189 & $0.207-6.837$ & 0.8464 \\
Male-to-male sex & 0.241 & $0.055-1.050$ & 0.0581 \\
Smoking & 2.004 & $0.581-6.911$ & 0.2713 \\
HCV carrier & 2.233 & $0.504-9.885$ & 0.2899 \\
Cancer & 7.782 & $1.909-31.731$ & 0.0042 \\
Antibiotic use within the past 1 year & 3.892 & $1.219-12.433$ & 0.0218 \\
\hline
\end{tabular}

Abbreviations: $H C V$ hepatitis $\mathrm{C}$ virus

predominant community-associated MRSA strain in the United States, on the basis of their being sequence type 8 by multilocus sequence typing (MLST), detection of arginine catabolic metabolic element (ACME) gene and harboring SCCmec type IV and genes for PVL. Three of them were characterized by ST30-SCCmec IV strains, known as the Southwest Pacific clone [2, 4]. One isolate characterized as sequence type 45 which had been identified as the predominate strain in nursing homes in Taiwan [36]. In this study, USA300 (ST8) accounted for four isolates and was a second most common clone. All four isolates were from NTUH. This is an emergent issue in Taiwan [35], which needs further surveillance and observation.

There were several limitations to the current study. First, less than $70 \%$ of the HIV-infected patients visiting CGMH and NTUH participated in this study which reduced the sample size and indirectly affected the analysis of statistical significance. It may be the reason for the lack of statistically significant association between MRSA colonization and the common risk factors reported in previous studies such as low CD4 T-cell count and hospitalization within the past year [37].

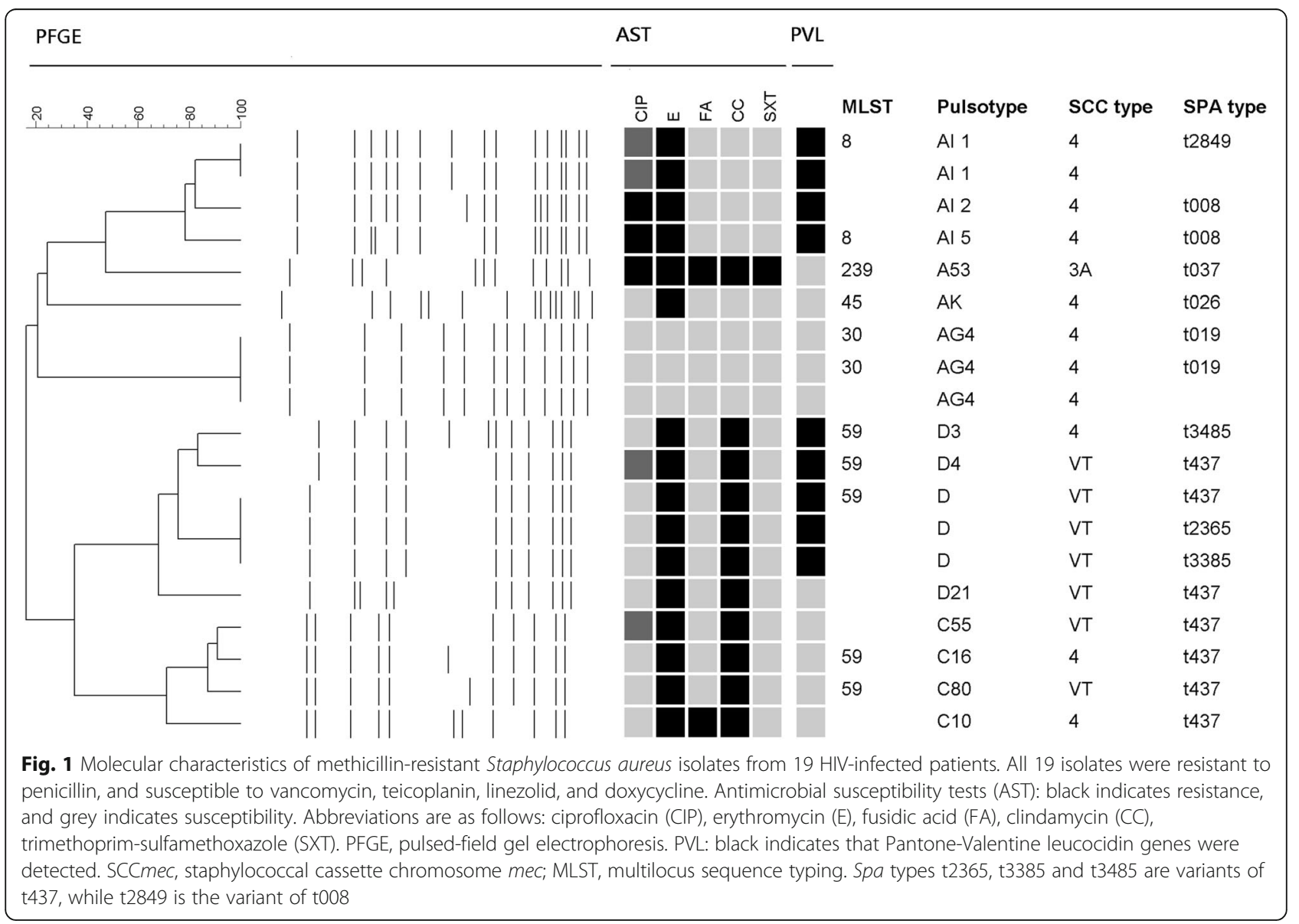


Second, the presence of other unrecognized sites of colonization should be considered. In this study, nasal specimens for MRSA detection were obtained by swabbing both anterior nares. Patients might be colonized in the inguinal, genital or peri-rectal areas but not in the nasopharynx [11, 37]. Other potential reasons for the disparity between the studies included the intermittent nature of colonization [10] and the difference in questionnaire design.

\section{Conclusions}

The prevalence of nasal MRSA colonization in HIVinfected patients seeking outpatient care was low (3.4\%) in northern Taiwan. Most of the colonizing isolates were genetically endemic community strains and exhibited high susceptible to TMP-SMX and fluoroqinolones. Cancer and antibiotic use within 1 year were associated with MRSA colonization. Nasal MRSA carriage in HIVinfected patients seeking outpatient care was low (3.4\%) in northern Taiwan.

\section{Abbreviations}

MRSA: Methicillin-resistant Staphylococcus aureus; MSSA: Methicillin-sensitive Staphylococcus aureus; CA: Community-associated; PFGE: Pulsed-field gel electrophoresis; MLST: Multilocus sequence typing; ST: Sequence type; PVL: Panton-Valentine leucocidin; ACME: Arginine catabolic metabolic element; HIV: Human immunodeficiency virus; HCV: Hepatitis C virus; ICU: Intensive care units

\section{Acknowledgements}

The authors thank the research assistants, Ya-Lin Huang and Yu-Chiao Huang for excellent technical assistance.

\section{Authors' contributions}

YYH and DW: laboratory performance, acquisition of data, analysis and interpretation of data, drafting the manuscript. $\mathrm{CCH}$ : acquisition of data, analysis and interpretation of data. SSH, FHY, MHL, CTH, PYH, SSS, CCY, CWC, HSL, TSW: acquisition of data and interpretation of data. YCH: conception and design, analysis and interpretation of data, modifying and revising the manuscript. All the authors read and approved the final manuscript.

\section{Funding}

The study was supported by a grant from the Ministry of Science and Technology, Executive Yuan, Taiwan (MOST 104-2815-C-182A-003B) and a grant from Medical Foundation in Memory of Dr. Deh-Lin Cheng. The funders had no role in the study design, data collection and analysis, decision to publish, or preparation of the manuscript.

\section{Availability of data and materials}

The datasets used and/or analysed during the current study are available from the corresponding author on reasonable request.

\section{Ethics approval and consent to participate}

The study was approved by the institutional review board of Chang Gung Memorial Hospital and the Research Ethics Committee of National Taiwan University Hospital. A written informed consent was obtained from each subject.

\section{Consent for publication}

Not applicable.

\section{Competing interests}

The authors declare that they have no competing interests.

\section{Author details}

'Department of Ophthalmology, Mackay Memorial Hospital, Taipei, Taiwan. ${ }^{2}$ Department of Internal Medicine, Cathay General hospital, Taipei, Taiwan. ${ }^{3}$ Department of Internal Medicine, National Taiwan University Hospital and National Taiwan University College of Medicine, Taipei, Taiwan. ${ }^{4}$ Department of Medicine, Chang Gung University School of Medicine, Kweishan, Taoyuan, Taiwan. ${ }^{5}$ Division of Infectious Diseases, Chang Gung Memorial Hospital at Keelung, Keelung, Taiwan. ${ }^{6}$ Division of Infectious Diseases, Chang Gung Memorial Hospital at Linkou, Kweishan, Taoyuan, Taiwan. ${ }^{7}$ Division of Pediatric Infectious Diseases, Chang Gung Memorial Hospital at Linkou, Kweishan, Taoyuan, Taiwan. ${ }^{8}$ Department of Pediatrics, Chang Gung Memorial Hospital, No. 5, Fu-Shin Street, Kweishan, 333 Taoyuan, Taiwan.

Received: 5 December 2019 Accepted: 17 March 2020

Published online: 30 March 2020

\section{References}

1. Jevons MP. "Celbenin"-resistant staphylococci. BMJ. 1961;1:124-5.

2. Chuang $Y Y$, Huang YC. Molecular epidemiology of community-associated meticillin-resistant Staphylococcus aureus in Asia. Lancet Infect Dis. 2013;13: 698-708.

3. David MZ, Daum RS. Community-associated methicillin-resistant Staphylococcus aureus: epidemiology and clinical consequences of an emerging epidemic. Clin Microbiol Rev. 2010;23:616-87.

4. Chen CJ, Huang YC. New epidemiology of Staphylococcus aureus infection in Asia. Clin Microbiol Infect. 2014;20:605-23.

5. von Eiff C, Becker K, Machka K, Stammer H, Peters G. Nasal carriage as a source of Staphylococcus aureus bacteremia. N Engl J Med. 2001;344:11-6.

6. Ellis MW, Hospenthal DR, Dooley DP, Gray PJ, Murray CK. Natural history of community-acquired methicillin-resistant Staphylococcus aureus colonization and infection in soldiers. Clin Infect Dis. 2004;39:971-9.

7. Popovich KJ, Weinstein RA, Aroutcheva A, Rice T, Hota B. Communityassociated methicillin-resistant Staphylococcus aureus and HIV intersecting epidemics. Clin Infect Dis. 2010;50:979-87.

8. Jacobson MA, Gellermann H, Chambers H. Staphylococcus aureus bacteremia and recurrent staphylococcal infection in patients with acquired immunodeficiency syndrome and AIDS-related complex. Am J Med. 1988; 85:172-6.

9. Witt DJ, Craven DE, McCabe WR. Bacterial infections in adult patients with the acquired immune deficiency syndrome (AIDS) and AIDSrelated complex. Am J Med. 1987;82:900-6.

10. Shet A, Mathema B, Mediavilla JR, Kishii K, Mehandru S, Jeane-Pierre P, et al. Colonization and subsequent skin and soft tissue infection due to methicillin-resistant Staphylococcus aureus in a cohort of otherwise healthy adults infected with HIV type 1. J Infect Dis. 2009;200:88-93.

11. Popovich JK, Hota B, Aroutcheva A, Kurien L, Patel J, Lyles-Banks R, et al. Community-associated methicillin-resistant Staphylococcus aureus colonization burden in HIV-infected patients. Clin Infect Dis. 2013;56:1067-74.

12. MCDonald LC, Lauderdale TL, Lo HJ, Tsai JJ, Hung CC. Colonization of HIVinfected outpatients in Taiwan with methicillin-resistant and methicillinsusceptible Staphylococcus aureus. Int J STD AIDS. 2003;14:473-7.

13. Padoveze MC, Pedro RJ, Da B-M, Bratfich OJ, Moretti ML. Staphylococcus aureus nasal colonization in HIV outpatients: persistent or transient? Am J Infect Control. 2008;36:187-91.

14. Delorenze GN, Horberg MA, Silverberg MJ, Tsai A, Quesenberry CP, Baxter R. Trends in annual incidence of methicillin-resistant Staphylococcus aureus (MRSA) infection in HIV-infected and HIV-uninfected patients. Epidemiol Infect. 2013;141:2392-402.

15. Sabbagh P, Riahi SM, Gamble HR, Rostami A. The global and regional prevalence, burden, and risk factors for methicillin-resistant Staphylococcus aureus colonization in HIV-infected people: a systematic review and metaanalysis. Am J Infect Control. 2019;47:323-33.

16. Popovich KJ, Smith KY, Khawcharoenporn T, Thurlow CJ, Lough J, Thomas $\mathrm{G}$, et al. Community-associated methicillin-resistant Staphylococcus aureus colonization in high-risk groups of HIV-infected patients. Clin Infect Dis. 2012:54:1296-303.

17. Onorato M, Borucki MJ, Baillargeon G, Paa DP, Freeman DH, Pat Cole C, Mayhall CG. Risk factors for colonization or infection due to methicillinresistant Staphylococcus aureus in HIV-positive patients: a retrospective casecontrol study. Infect Control Hosp Epidemiol. 1999;20:26-30. 
18. Oliva A, Lichtner M, Mascellino MT, lannetta M, lalungo AM, Tadadjeu Mewamba S, et al. Study of methicillin-resistant Staphylococcus aureus (MRSA) carriage in a population of HIV-negative migrants and HIV-infected patients attending an outpatient clinic in Rome. Ann Ig. 2013;25:99-107.

19. Imaz A, Cobos-Trigueros N, Falcó V, Dominguez MA, Manzardo C, Pujol M, et al. Community-associated methicillin-resistant Staphylococcus aureus infections in HIV-infected patients in Spain. J Inf Secur. 2013;66:199-201.

20. Joore IKCW, Rooijen MSV, Loeff MFSVD, Neeling AJD, Dam AV, Vries HJCD. Low prevalence of methicillin-resistant Staphylococcus aureus among men who have sex with men attending an STI clinic in Amsterdam: a crosssectional study. BMJ. 2013;3:002505.

21. Kyaw WM, Lee LK, Siong WC, Ping AC, Ang B, Leo YS. Prevalence of and risk fac- tors for MRSA colonization in HIV-positive outpatients in Singapore. AIDS Res Ther. 2012;9:33.

22. Cenizal MJ, Hardy RD, Anderson M, Katz K, Skiest DJ. Prevalence of and risk factors for methicillin-resistant Staphylococcus aureus (MRSA) nasal colonization in HIV-infected ambulatory patients. J Acquir Immune Defic Syndr. 2008;48:567-71.

23. Wu CJ, Ko WC, Ho MW, Lin HH, Yang YL, Lin JN, et al. Prevalence of and risk factors for methicillin-resistant Staphylococcus aureus colonization among human immunodeficient virus-infected outpatients in Taiwan: oral Candida colonization as a comparator. J Oral Microbiol. 2017;9:1322446.

24. Clinical and Laboratories Standards Institute. Performance standards for antimicrobial susceptibility testing; 21 st informational supplement. M100s21. 2011

25. Huang YC, Ho CF, Chen CJ, Su LH, Lin TY. Comparative molecular analysis of community-associated and healthcare-associated methicillin-resistant Staphylococcus aureus isolates from children in northern Taiwan. Clin Microbiol Infect. 2008;14:1167-72.

26. Huang YC, Su LH, Wu TL, Lin TY. Methicillin-resistant Staphylococcus aureus nasal carriage in international medical conference attendees. J Microbiol Immunol Infect. 2019;52:242-7.

27. Tsai MS, Chen CJ, Lin TY, Huang YC. Nasal methicillin-resistant Staphylococcus aureus colonization among otherwise healthy children aged between 2 months and 5 years in northern Taiwan, 2005-2010. J Microbiol Immunol Infect. 2018;51:756-62.

28. Oliveira DC, de Lencastre H. Multiplex PCR strategy for rapid identification of structural types and variants of the mec element in methicillin-resistant Staphylococcus aureus. Antimicrob Agents Chemother. 2002;46:2155-61.

29. Enright MC, Day NP, Davies CE, Peacock SJ, Spratt BG. Multilocus sequence typing for characterization of methicillin-resistant and methicillin-susceptible clones of Staphylococcus aureus. J Clin Microbiol. 2000;38:1008-15.

30. Chen CB, Chang HC, Huang YC. Nasal meticillin-resistant Staphylococcus aureus carriage among intensive care unit hospitalised adult patients in a Taiwanese medical centre: one time-point prevalence, molecular characteristics and risk factors for carriage. J Hosp Infect. 2010;74:238-44.

31. Kang YC, Tai WC, Yu CC, Kang JH, Huang YC. Methicillin-resistant Staphylococcus aureus nasal carriage among patients receiving hemodialysis in Taiwan: prevalence rate, molecular characterization and de-colonization. BMC Infect Dis. 2012;12:284.

32. Lu SY, Chang FY, Cheng CC, Lee KD, Huang YC. Methicillin-resistant Staphylococcus aureus nasal colonization among adult patients visiting emergency department in a medical center in Taiwan. PLoS One. 2011;6: e18620

33. Wang JT, Liao CH, Fang $C T$, Chie WC, Lai MS, Lauderdale $T L$, et al. Prevalence of and risk factors for colonization by methicillin-resistant Staphylococcus aureus among adults in community settings in Taiwan. J Clin Microbiol. 2009;47:2957-63.

34. Touboul-Lundgren $P$, Jensen S, Drai J, Lindbæk M. Identification of cultural determinants of antibiotic use cited in primary care in Europe: a mixed research synthesis study of integrated design "culture is all around us". BMC Public Health. 2015;15:908.

35. Huang YC, Chen CJ, Kuo CC, Lu MC. Emergence, transmission and phylogeny of methicillin-resistant Staphylococcus aureus sequence type 8 (USA300) in Taiwan. J Hosp Infect. 2018;100:355-8.

36. Tsao FY, Kou HW, Huang YC. Dissemination of methicillin-resistant Staphylococcus aureus sequence type 45 among nursing home residents and staff in Taiwan. Clin Microbiol Infect. 2015;21:451-8.

37. Zervou FN, Zacharioudakis IM, Ziakas PD, Rich JD, Mylonakis E. Prevalence of and risk factors for methicillin-resistant Staphylococcus aureus colonization in HIV infection: a meta-analysis. Clin Infect Dis. 2014;59:1302-11.

\section{Publisher's Note}

Springer Nature remains neutral with regard to jurisdictional claims in published maps and institutional affiliations.
Ready to submit your research? Choose BMC and benefit from:

- fast, convenient online submission

- thorough peer review by experienced researchers in your field

- rapid publication on acceptance

- support for research data, including large and complex data types

- gold Open Access which fosters wider collaboration and increased citations

- maximum visibility for your research: over $100 \mathrm{M}$ website views per year

At BMC, research is always in progress.

Learn more biomedcentral.com/submissions 